\title{
Profile Of Chronic Rhinosinusitis Patients That Undergo Functional Endoscopic Sinus Surgery At Dr. Soetomo General Hospital Year 2015-2019
}

\author{
Ardiar Rahmannanda Laksanadi ${ }^{1}$, Budi Sutikno ${ }^{2}$, Sahudi $^{3}$ \\ 1 ardiar.rahmannanda.laksanadi-2018@fk.unair.ac.id \\ ${ }^{1}$ Medical Study Program, Faculty of Medicine, University of Airlangga 60132, Surabaya, Indonesia \\ ${ }^{2}$ Departement of Otorhinolaryngology Head and Neck Surgery, Dr. Soetomo General Hospital, \\ University of Airlangga 60132, Surabaya, Indonesia \\ ${ }^{3}$ Departement of Head and Neck Surgery Dr. Soetomo General Hospital, University of Airlangga 60132, Surabaya, Indonesia
}

\begin{abstract}
Background: Rhinosinusitis is an inflammation that occurs in the nose and paranasal sinuses, characterized by two or more symptoms, and one of the symptoms that must be present is nasal obstruction, facial pain, olfactory disturbances, and nasal discharge (anterior, posterior nasal drip). Chronic rhinosinusitis with nasal polyps has 3 different degrees of severity based on the way of treatment, the initial treatment that is always applied to all levels of severity is topical steroid administration, nasal irrigation using $\mathrm{NaCl}$ nasal wash solution, and given topical steroids. Methods: This study used a retrospective descriptive method with medical records of patients with chronic rhinosinusitis at The ENT Outpatient Unit Dr. Soetomo General Hospital for the period January 2015 until December 2019. Results: Obtained 99 samples, with details of 72 inclusion samples and 27 exclusion samples due to incomplete data. Conclusion: There are more women than men with majority of young adults, the most common complaint is nasal obstruction, the most common risk factors are allergies and gastric reflux, the highest score of SNOT-22 is 0-22, followed by 23-44, LundKennedy scored the most at $0-4$, followed by 5-8, Lund-Mackay scored the most at 5-8 followed by 0-4, most diagnoses are CRS without polyps.
\end{abstract}

Keywords: Rhinosinusitis; nasal; polyp; profile; inflammation; chronic respiratory disease

\section{Introduction}

Rhinosinusitis is widely known as inflammation of the nose and paranasal sinuses characterized by two or more symptoms, and one of the symptoms that must be present is nasal obstruction, facial pain, olfactory disturbances, and discharge from the nose (anterior, posterior nasal drip). Chronic rhinosinusitis (CRS) lasts 12 weeks or more, diagnosed according to European criteria Position Paper on Rhinosinusitis and Nasal Polyps 2020 (EPOS 2020) in the form of rhinorrhea, nasal congestion, facial pain or pressure, and smelling disturbances [1] [2]. Nowadays, CRS continues to develop as a serious health problem as it results in a financial burden on the society. Several guidelines, consensus documents, and papers regarding rhinosinusitis and nasal polyposis were seemed to have developed in the last decade [3].

Several instruments are used to strengthen the diagnosis of CRS. The use of the Visual Analog Scale (VAS) has been shown to be clinically relevant in measuring the severity of each symptom subjectively as felt 
by the patient. In addition to VAS, the severity or quality of life of patients with CRS can also be assessed using Sinonasal Outcome Test-22 (SNOT-22) questionnaire. Currently, this questionnaire is the most specific tool to assess CRS patients' quality of life [4]. Moreover, endoscopic and radiologic measures were also used. Lund-Kennedy score assesses the inflammation level of nasal cavity, while Lund-Mackay score assesses paranasal sinuses [5] [6].

Based on the data provided by the ENT department of Dr. Hasan Sadikin general hospital, Bandung, Indonesia (2011), 45\% of rhinosinusitis cases were recorded in the polyclinic Allergic rhinology, consisting of 46.04\% male and $53.86 \%$ female. The prevalence of CRS was more commonly found in women than men with the ratio of 6:4 [7]. Meanwhile, in Canada CRS prevalence was more detectable in men than women and was found to be increasing with age ranging between 20-29 and 50-59 years [1]. Since CRS seemed to have different prevalence and distribution in different regions and surely need consequential management, this study aims to learn the profile of CRS patients that undergo functional endoscopic sinus surgery at Dr. Soetomo general hospital Surabaya, Indonesia.

\section{Method}

This study used a retrospective descriptive design based on medical records of chronic rhinosinusitis patients and carried out after approval from Dr. Soetomo general hospital ethical committee. Subjects of this study were collected through total sampling technique, involving a population of chronic rhinosinusitis patients that undergo functional endoscopic sinus surgery at Dr. Soetomo general hospital ENT outpatient unit from the year 2015 to 2019. Subjects with incomplete data were then excluded from this study. All cases were obtained according to the variables researched, processed, and then served as tables and diagrams subsequently.

\section{Result}

This research was conducted at the Dr. Soetomo General Hospital Surabaya, Indonesia. Obtained 72 samples year 2015-2019 medical records of chronic rhinosinusitis patients that undergo functional endoscopic sinus surgery and excluded 27 samples because some of the data is incomplete.

Table 1. Data on Age Distribution of Chronic Rhinosinusitis Patients That Undergo Functional Endoscopic Sinus Surgery at Dr. Soetomo Hospital Surabaya

\begin{tabular}{|c|c|c|}
\hline Age & Frequency (n) & Percentage $(\%)$ \\
\hline$\leq 10$ years & 2 & 2.78 \\
\hline 11-20years & 17 & 23.61 \\
\hline 21-30years & 9 & 12.5 \\
\hline 31-40years & 14 & 19.44 \\
\hline 41-50years & 16 & 22.22 \\
\hline 51-60years & 11 & 15.28 \\
\hline $61-70$ years & 3 & 4.17 \\
\hline$>70$ years & 0 & 0 \\
\hline Total & 72 & 100 \\
\hline
\end{tabular}

Based on the results obtained in this study, the largest sample of CRS patient data was found in the 11-20 years age group (23.61\%), and the number begins to decline at the age of 51-60, followed by with less people in the age group $61-70$ and $>70$ years. CRS patients in the age group of $\leqslant 10$ years are only a few in 
number, which indicates that the incidence of CRS increased starting at the age of puberty. Similar findings also state that the distribution of CRS patients was found mostly in the age range of 15-24 years, yet there isn't any definite reason that underlies this finding [8] [9].

Table 2. Data on Sex Distribution of Chronic Rhinosinusitis Patients That Undergo Functional Endoscopic Sinus Surgery at Dr. Soetomo Hospital Surabaya

\begin{tabular}{llll}
\hline Sex & & Frequency $(\mathrm{n})$ & Percentage $(\%)$ \\
\hline Male & 34 & 47.22 \\
Female & & 38 & 52.78 \\
& & 72 & 100 \\
\hline
\end{tabular}

The results showed that the majority of the samples were female patients, as many as 38 patients $(52.781 \%)$, then male patients, as many as 34 patients $(47.22 \%)$.

Table 3. Data on Main Symptom Distribution of Chronic Rhinosinusitis Patients That Undergo Functional Endoscopic Sinus Surgery at Dr. Soetomo Hospital Surabaya

\begin{tabular}{|c|c|c|}
\hline Main symptom & Frequency $(\mathrm{n})$ & Percentage $(\%)$ \\
\hline Nasal obstruction & 33 & 45.83 \\
\hline Rhinorrhea & 5 & 6.94 \\
\hline Facial pain/pressure & 6 & 8.33 \\
\hline Hyposmia & 0 & 0 \\
\hline Coughing & 0 & 0 \\
\hline Others & 28 & 38.90 \\
\hline Total & 72 & 100 \\
\hline
\end{tabular}

From the data above showed that the majority of the samples main symptom was nasal obstruction, as many as 33 patients $(45.83 \%)$, followed by Others as many as 28 patients $(38.90 \%)$, then facial pain/pressure 6 patients $(8.33 \%)$, and then Rhinorrhea as many as 5 patients $(6.94 \%)$, and the last two ones are hyposmia and coughing none $(0 \%)$ of the patients had that main symptom.

Table 4. Data on Risk Factor Distribution of Chronic Rhinosinusitis Patients That Undergo Functional Endoscopic Sinus Surgery at Dr. Soetomo Hospital Surabaya

\begin{tabular}{lll}
\hline Risk factor & Frequency $(\mathrm{n})$ & Percentage $(\%)$ \\
\hline Allergy & 14 & 19.44 \\
Asthma & 3 & 4.17 \\
Gastric reflux & 14 & 19.44 \\
Smoking & 10 & 13.89 \\
Others & 1 & 1.39 \\
Without risk factor & 30 & 41.67 \\
$\quad$ Total & 72 & 100 \\
\hline
\end{tabular}


The results showed that the majority of the risk factor is without risk factor patients, as many as 30 patients $(41.67 \%)$, then allergy and gastric reflux patients, as many as 14 patients $(19.44 \%)$, after that patients with smoking habit as many as 10 patients $(13.89 \%)$, and then pastients with asthma that is 3 patients $(4.17 \%)$, and the last one is patient with other risk factor only 1 patient $(1.39 \%)$.

Table 5. Data on SNOT-22 Score Distribution of Chronic Rhinosinusitis Patients That Undergo Functional Endoscopic Sinus Surgery at Dr. Soetomo Hospital Surabaya

\begin{tabular}{|c|c|c|}
\hline SNOT-22 score & Frequency (n) & Percentage $(\%)$ \\
\hline $0-22$ & 38 & 52.78 \\
\hline $23-44$ & 22 & 30.56 \\
\hline $45-66$ & 7 & 9.72 \\
\hline $67-88$ & 5 & 6.94 \\
\hline $89-110$ & 0 & 0 \\
\hline Total & 72 & 100 \\
\hline
\end{tabular}

The results showed that the majority of SNOT-22 Score in patients is $0-22$, as many as 38 patients $(52.78 \%)$, then score $23-44$ as many as 22 patients $(30.56 \%)$, followed by the score of $45-66$ as many as 7 paatients $(9.72 \%)$, and then patients with score $67-88$ is 5 patients $(6.94 \%)$, and the last one none $(0 \%)$ of the patient score 89-110.

Table 6. Data on Lund-Kennedy Score Distribution of Chronic Rhinosinusitis Patients That Undergo Functional Endoscopic Sinus Surgery at Dr. Soetomo Hospital Surabaya

\begin{tabular}{|c|c|c|}
\hline Lund-Kennedy score & Frequency (n) & Percentage $(\%)$ \\
\hline $0-4$ & 40 & 55.56 \\
\hline $5-8$ & 23 & 31.94 \\
\hline $9-12$ & 9 & 12.50 \\
\hline Total & 72 & 100 \\
\hline
\end{tabular}

The results showed that the majority of Lund-Kennedy Score in patients is 0-4, as many as 40 patients $(55.56 \%)$, then score 5-8 as many as 23 patients $(31.94 \%)$, followed by the score of $9-12$ as many as 9 paatients $(12.50 \%)$.

Table 7. Data on Lund-Mackay Score Distribution of Chronic Rhinosinusitis Patients That Undergo Functional Endoscopic Sinus Surgery at Dr. Soetomo Hospital Surabaya

\begin{tabular}{|c|c|c|}
\hline Lund-Mackay score & Frequency (n) & Percentage $(\%)$ \\
\hline $0-4$ & 19 & 26.39 \\
\hline $5-8$ & 21 & 29.17 \\
\hline $9-12$ & 10 & 13.89 \\
\hline $13-16$ & 5 & 6.94 \\
\hline $17-20$ & 6 & 8.33 \\
\hline $21-24$ & 11 & 15.28 \\
\hline Total & 72 & 100 \\
\hline
\end{tabular}


The results showed that the majority of Lund-Mackay Score in patients is 5-8, as many as 21 patients $(29.17 \%)$, and then the minority score is $13-16$, as many as 5 patients $(6.94 \%)$.

Table 8. Data on Variety of Diagnosis Distribution of Chronic Rhinosinusitis Patients That Undergo Functional Endoscopic Sinus Surgery at Dr. Soetomo Hospital Surabaya

\begin{tabular}{|c|c|c|}
\hline Variety of diagnosis & Frequency (n) & Percentage $(\%)$ \\
\hline CRSsNP & 38 & 52.77 \\
\hline CRSwNP & 22 & 30.56 \\
\hline Antrochoanal polyp & 10 & 13.89 \\
\hline Dentogenous sinusitis & 1 & 1.39 \\
\hline Mucocele & 1 & 1.39 \\
\hline Total & 72 & 100 \\
\hline
\end{tabular}

The results showed that the majority of Variety diagnosis in patients is CRSsNP, as many as 38 patients $(52.77 \%)$, and then the minority of variety diagnosis in patients is Dentogenous sinusitis and Mucocele, only just 1 patient (1.39\%).

\section{Discussion}

This study used a descriptive with a retrospective approach, which used secondary data in the form of medical records of chronic rhinosinusitis patients that undergo functional endoscopic sinus surgery at Dr. Soetomo General Hospital year 2015-2019.

From the data obtained in the ENT Outpatient Unit, Dr. Soetomo general hospital, Surabaya, Indonesia in the period from January to December 2015-2019, it was found that the total CRS patients who underwent FESS and met the inclusion criteria were a total of 72 patients. 27 samples were excluded from this study because some of the data from these samples were incomplete. Although CRS can happen at any age, Fokkens et al (2012) found that CRS prevalence rise after puberty and gradually decreases in middle to old age [1]. Based on the results obtained in this study, the largest sample of CRS patient data was found in the 11-20 years age group (23.61\%), and the number begins to decline at the age of 51-60, followed by with less people in the age group 61-70 and $>70$ years. CRS patients in the age group of $\leq 10$ years are only a few in number, which indicates that the incidence of CRS increased starting at the age of puberty. Similar findings also state that the distribution of CRS patients was found mostly in the age range of 15-24 years, yet there isn't any definite reason that underlies this finding [8] [9]. However, studies regarding age distribution of CRS patients remain inconsistent. Several studies found that the incidence of CRS increases with age and is mostly found in the elderly [10] [11]. This is due to changes in mucociliary function and defects in central microtubule cilia, resulting in increased risk of CRS in the elderly [12]. A study conducted by Xu et al (2016) found that the prevalence of CRS increases starting at the age group of 18-20 years and declines at the oldest age group [13]. This finding supports the result of this study, where the incidence of CRS remains high in the adult age group following the increase of numbers at the age of puberty. Therefore, the findings in this study suggests that the distribution of CRS tends to increase starting at the age of puberty, stays consistently high at the adult age, and then drops at the elderly age (>60 years), keeping in mind that this pattern may be due to several other factors (e.g. race and genetics) thus the result can vary according to each region.

Different findings regarding sex distribution in patients with CRS remain inconsistent. United States epidemiology study reported CRS ratio between female and male is 6:4, while Canada epidemiology reported more male suffer from CRS than female [14]. However, previous studies found that there is no significant 
difference between both male and female prevalence of CRS [15]. In this study, although more female are found to suffer from CRS, there's only $5.56 \%$ difference in number between both sexes. This may be due to female's anatomic structure of the sinus tend to be smaller than male, resulting in susceptibility to nasal obstruction and further infection [16]. Ference et al (2015) suggests that these contradictions illustrate various factors, including methodology, definitions used in each study, also intrinsic differences in sex-specific prevalence of CRS in different parts of the world [15].

Symptoms experienced by CRS patients can differ for each person. According to the American Academy of Otolaryngologic Allergy - Head and Neck Surgery, there are 4 main symptoms of CRS, namely nasal obstruction, facial pain/pressure, purulent secrete, and hyposmia [17]. Out of the total sample in this study, $45.83 \%$ experience nasal obstruction. Previous studies that have been conducted also found nasal obstruction as the most occurring symptom in patients diagnosed with CRS, suggesting that it may be due to prolonged mucociliary clearance resulting in the build-up of foreign particles and later cannot be expelled from the nose [2] [18]. This irreversible mucosa condition causes persistent nasal obstruction symptoms in CRS, thus making it the most frequently encountered symptom in CRS patients. After nasal obstruction, facial pain/pressure and rhinorrhea follow as symptoms that are most commonly found among the CRS patients. Aside from the main symptoms, other symptoms such as epistaxis, bloody secrete, and eye swelling were also found in this study (38.9\%). Epistaxis can occur in CRS with granulomatous diseases like vasculitis and sarcoidosis, while eye swelling can occur as a result of orbital complication of CRS [17] [19] [20].

There are several risk factors of CRS, namely allergy, asthma, air pollution, smoking, metabolic syndromes, and obesity [2]. Results of this study show that CRS patients mostly (41.67\%) do not have any risk factor. However, allergy and gastric reflux are risk factors that were most found in CRS patients. A study conducted by Kim et al (2011) found allergic rhinitis as the most significant risk factor of CRS in Korea, supported by findings of Kim et al (2016) that showed allergic rhinitis prevalence had the biggest number among other risk factors of CRS [10] [21]. Allergic reaction towards aspirin were also reported previously in 36-96\% patients diagnosed with CRS [2]. Marcus et al (2019) suggested that allergic diseases, especially IgE-mediated inflammatory processes, are thought to be a triggering factor for CRS through allergy-induced mucosal inflammation, causing sinus ostium obstruction and further secondary infection [22]. Gastric reflux association to CRS is currently being investigated. Kim et al (2019) reported GERD (gastroesophageal reflux disease) are found more in CRS patients than in the control group, and odd ratio of GERD increases in CRS patients. The association between CSR and GERD remain controversial until now since the etiology of CRS and GERD are mutually overlapping. Gastric reflux can trigger rhinitis from vagus nerve reflex mediation or activation of neural reflexes in the nasal cavity. Stimulation of the esophagus by HCL can stimulate the production of nasal mucus and decreases nasal patency. Cough, as one of the symptoms of CRS, can worsen the symptoms of GERD [23].

SNOT-22 scoring system plays a role in the assessment of patients' severity. This questionnaire consists of 22 questions, divided into 4 domains namely nasal symptoms, facial or ear symptoms, sleep disturbances and psychological changes, which then facilitates the assessment of these 4 domains [4] [24]. Toma and Hopkins (2016) studied a valid stratification in the use of SNOT-22 using the MMS classification (mild, moderate, severe). 65 CRS patients' SNOT-22 scores and VAS scores were evaluated and then compared and correlated to the severity and quality of life of the patient. From this study, they concluded that the SNOT-22 score of 8-20 was considered mild, 20-50 was considered moderate, and finally >50 was considered severe [25]. Of all CRS patients included in this study, 38 people $(52.78 \%)$ had SNOT-22 score of 0-22. These results indicate that approximately half of the total sample - i.e., most of the CRS patients, had a degree of mild severity. Following mild severity is moderate, with a total number of $30.56 \%$ patients with SNOT-22 score of 23-44. Only a small part of the sample of this study has SNOT-22 scores of 45-66 and 6788 , in which they experience severe symptoms, taking count $16.66 \%$ of the total CRS patients. 
Lund-Kennedy scoring system is an assessment based on polyp, edema, and secrete endoscopic results. The modified version of Lund-Kennedy is known to correlate well with SNOT-22 scores and is useful for pre and post sinus surgery case study [26]. The results of this study found that the prevalence of CRS patients assessed using the Lund-Kennedy score was mostly found with a score scale of 0-4 (55.56\%), followed by a score scale of 5-8 (31.94\%), and finally a score scale of 9-12 (12.50\%). This finding is in line with a study conducted by Nathan et al (2021), where most CRS patients had a score of 0-4 (group scores <2 and 2-4), followed by a score of 5-8 and a score of 9-12 with the same number of patients. Higher LundKennedy score signifies worse observed disease; thus, it can be concluded that CRS patients in this study mostly have good endoscopy results, leading to better quality of life and prognosis [27].

Lund-Mackay scoring system based on radiologic results is needed in considering the diagnosis of CRS patients. Paranasal sinuses inflammation level can be assessed through Lund-Mackay scoring. Previous studies suggested that Lund-Mackay scores highly correlates with degree of severity and was found as an indicator of CRS patients' quality of life, indicating the severity of CRS can be evaluated from the results of patient's radiological score [28] [29]. Brooks et al (2018) conducted a similar study on patients diagnosed with CRS that undergo FESS using Lund-Mackay scores and divided them into quartiles, i.e. score of 1-8, score of 9-12, score of 13-16, and score of 17-24 [29]. The general characteristics of the research sample found the highest number of patients classifies in the first quartile with a score of 1-8, and the least number of patients classifies in the third quartile with a score of 13-16. These findings are in line with the results of this study. After undergoing FESS, the lowest quartile (score 1-8) had the lowest average change of SNOT-22 score. Interestingly, patients in the highest quartile of the preoperative Lund-Mackay score (score 17-24) had the greatest postoperative improvement. This indicates that higher Lund-Mackay preoperative scores predict a better postoperative quality of life outcome. If implemented in this study, 11 people (15.28\%) with LundMackay scores of 21-24 has a chance of having good postoperative quality of life. In addition, Hopkins et al (2007) suggested that patients with high Lund-Mackay scores undergo more extensive surgery yet experience more reduction of symptoms after surgery [30].

Similar to other diseases in general, CRS also has various differential diagnosis, thus scoring methods previously mentioned is needed in order to narrow down other diagnoses of the disease. The diagnosis of CRS requires accurate methods based on clinical and supporting results such as endoscopy and CT scan and does not only based on history of illness. In this study, most patients were diagnosed with CRS without polyp (CRSsNP), taking count of approximately half of the population studied (52.77\%). This number is later followed by CRS with polyp/CRSwNP (30.56\%). However, diagnoses other than CRS were also found, such as antrochoanal polyp, dentogenous sinus, and mucocele. CRSsNP is known to have a higher prevalence than CRSwNP, and CRSwNP polyps is known to occur in 25-30\% of the patient population with CRS [31] [32]. The findings of this study obtained the same results. The cause of nasal polyps in CRS is not yet known with certainty, hence need further investigation.

For future studies, bigger sample size can be used to obtain more representative results. The completion of medical record data is important in retrospective research, as it affects the number of samples studied.

\section{Conclusion}

This present study concluded that among chronic rhinosinusitis patients that undergo functional endoscopic sinus surgery at Dr. Soetomo general hospital ENT outpatient unit from the year 2015 to 2019, young adults age group is most commonly found with more women than men prevalence. Nasal obstruction is mostly complained among the patients, and allergy as well as gastric reflux were the most common risk factors. Chronic rhinosinusitis patients mostly score 0-22 for SNOT-22, 0-4 for Lund-Kennedy, and 5-8 for LundMackay. The population studied was mostly diagnosed with CRS without polyp (CRSsNP). 


\section{Acknowledgement}

The authors would like to thank the Director of Dr. Soetomo General Hospital and Departement of Otorhinolaryngology Head and Neck Surgery Dr. Soetomo General Hospital for supporting this research.

\section{References}

[1] Fokkens, W.J., Lund, V.J., Mullol, J., Bachert, C., Alobid, I., Baroody, F., Cohen, N., Cervin, A., Douglas, R., Gevaert, P. and Georgalas, C., 2012. EPOS 2012: European position paper on rhinosinusitis and nasal polyps 2012. A summary for otorhinolaryngologists. Rhinology, 50(1), pp.1-12.

[2] Fokkens, W., Lund, V., Hopkins, C., Hellings, P., Kerns, R., Reitsma, S., Toppila-Salmi, S., Bernal-Sprekelsen, M., Mullol, J., Alobid, I. and Urbančič, J., 2020. European Position Paper on Rhinosinusitis and Nasal Polyps 2020. Leiden: International Rhinologic Society.

[3] Fokkens, W., Lund, V., Bachert, C., Clement, P., Helllings, P., Holmstrom, M., Jones, N., Kalogjera, L., Kennedy, D., Kowalski, M. and Malmberg, H., 2005. European position paper on rhinosinusitis and nasal polyps. Rhinology, 23(23), pp.187.

[4] Hopkins C, Gillett S, Slack R, Lund V, Browne J. Psychometric validity of the 22-item Sinonasal Outcome Test. Clin Otolaryngol. 2009; 34:447-454.

[5] Lund, V.J. and Kennedy, D.W., 1995. Staging and Therapy Group. Quantification for staging sinusitis. Ann Otol Rhinol Laryngol Suppl, 167, pp.17-21.

[6] Lund, V.J. and Mackay, I.S., 1993. Staging in rhinosinusitis. Rhinology, 31, pp.183-183.

[7] Prastianingsih P, Madiadipoera T, Lasminingrum L., 2006. Perbandingan jumlah eosinofil dan kadar IL-5 pada mukosa hidung antara rinosinusitis kronis disertai polip hidung dengan yang tanpa polip hidung [tesis]. Bandung: Universitas Padjadjaran

[8] Firman S, 2011. Gambaran pola kuman aerob di sinus maksila pada penderita Rinosinusitis Maksila Kronik yang dilakukan tindakan pembedahan di RSUP H. Adam Malik Medan. Dalam: Tesis Bagian THT-KL FK Universitas Sumatera Utara Medan.

[9] Dewi, E., 2013. Profil Penderita Rinosinusitis Kronik yang Menjalani Tindakan Bedah Sinus Endoskopik Fungsional di RSUP H. Adam Malik Medan Tahun 2008-2011.

[10] Kim, Y.S., Kim, N.H., Seong, S.Y., Kim, K.R., Lee, G.B. and Kim, K.S., 2011. Prevalence and risk factors of chronic rhinosinusitis in Korea. American journal of rhinology \& allergy, 25(3), pp. e117-e121.

[11] Chen, Y., Dales, R. and Lin, M., 2003. The epidemiology of chronic rhinosinusitis in Canadians. The Laryngoscope, 113(7), pp.1199-1205.

[12] Ho, J.C., Chan, K.N., Hu, W.H., Lam, W.K., Zheng, L., Tipoe, G.L., Sun, J., Leung, R. and Tsang, K.W., 2001. The effect of aging on nasal mucociliary clearance, beat frequency, and ultrastructure of respiratory cilia. American journal of respiratory and critical care medicine, 163(4), pp.983-988.

[13] Xu, Y., Quan, H., Faris, P., Garies, S., Liu, M., Bird, C., Kukec, E., Dean, S. and Rudmik, L., 2016. Prevalence and incidence of diagnosed chronic rhinosinusitis in Alberta, Canada. JAMA otolaryngology-head \& neck surgery, 142(11), pp.1063-1069.

[14] Baumann, I., Blumenstock, G., DeMaddalena, H., Piccirillo, J.F. and Plinkert, P.K., 2007. Quality of life in patients with chronic rhinosinusitis: validation of the Sino-Nasal Outcome Test-20 German Adapted Version. Hno, 55(1), pp.42-47.

[15] Ference, E.H., Tan, B.K., Hulse, K.E., Chandra, R.K., Smith, S.B., Kern, R.C., Conley, D.B. and Smith, S.S., 2015. Commentary on gender differences in prevalence, treatment, and quality of life of patients with chronic rhinosinusitis. Allergy \& Rhinology, 6(2), pp.ar-2015.

[16] Soetjipto D. 2006. Berbagai Aspek Sinusitis dan Hubungan dengan Alergi. Dalam Kumpulan Naskah Simposium Nasional Perkembangan Terkini Penatalaksanaan Beberapa Penyakit Penyerta Rinitis Alergi. h.10-5

[17] Sedaghat, A.R., 2018. Chronic rhinosinusitis. Infections of the Ears, Nose, Throat, and Sinuses, pp.155-168.

[18] Bengtsson, C., Lindberg, E., Jonsson, L., Holmström, M., Sundbom, F., Hedner, J., Malinovschi, A., Middelveld, R., Forsberg, B. and Janson, C., 2017. 'Chronic rhinosinusitis impairs sleep quality: results of the GA2LEN study'. Sleep, vol 40(1), p.zsw021.

[19] Reed, J., deShazo, R.D., Houle, T.T., Stringer, S., Wright, L. and Moak III, J.S., 2010. Clinical features of sarcoid rhinosinusitis. The American journal of medicine, 123(9), pp.856-862.

[20] Chandler, J.R., Langenbrunner, D.J. and Stevens, E.R., 1970. The pathogenesis of orbital complications in acute sinusitis. The Laryngoscope, 80(9), pp.1414-1428.

[21] Kim, J.H., Cho, C., Lee, E.J., Suh, Y.S., Choi, B.I. and Kim, K.S., 2016. Prevalence and risk factors of chronic rhinosinusitis in South Korea according to diagnostic criteria. Rhinology, 54(4), pp.329-335.

[22] Marcus, S., Roland, L.T., DelGaudio, J.M. and Wise, S.K., 2019. The relationship between allergy and chronic rhinosinusitis. Laryngoscope investigative otolaryngology, 4(1), pp.13-17. 
[23] Kim, S.Y., Park, B., Lim, H., Kim, M., Kong, I.G. and Choi, H.G., 2019, April. Gastroesophageal reflux disease increases the risk of chronic rhinosinusitis: a nested case-control study using a national sample cohort. In International forum of allergy \& rhinology (Vol. 9, No. 4, pp. 357-362).

[24] Abdalla, S., Alreefy, H. and Hopkins, C., 2012. 'Prevalence of sinonasal outcome test (SNOT-22) symptoms in patients undergoing surgery for chronic rhinosinusitis in the England and Wales National prospective audit'. Clinical otolaryngology, 37(4), pp.276-282.

[25] Toma, S. and Hopkins, C., 2016. Stratification of SNOT-22 scores into mild, moderate or severe and relationship with other subjective instruments. Rhinology, 54(2), pp.129-133.

[26] Psaltis, A.J., Li, G., Vaezeafshar, R., Cho, K.S. and Hwang, P.H., 2014. Modification of the Lund-Kennedy endoscopic scoring system improves its reliability and correlation with patient-reported outcome measures. The Laryngoscope, 124(10), pp.22162223 .

[27] Nathan, K., Majhi, S.K., Bhardwaj, R., Gupta, A., Ponnusamy, S., Basu, C. and Kaushal, A., 2021. The Role of Diagnostic Nasal Endoscopy and a Computed Tomography Scan (Nose and PNS) in the Assessment of Chronic Rhinosinusitis: A Comparative Evaluation of the Two Techniques. Sinusitis, 5(1), pp.59-66.

[28] Caliaperoumal, V.B.B., Dharanya, G.S., Velayutham, P., Balasubramanian Krishnaswami, K.K.R.K. and Savery, N., 2021. Correlation of Clinical Symptoms with Nasal Endoscopy and Radiological Findings in the Diagnosis of Chronic Rhinosinusitis: A Prospective Observational Study. Cureus, 13(7).

[29] Brooks, S.G., Trope, M., Blasetti, M., Doghramji, L., Parasher, A., Glicksman, J.T., Kennedy, D.W., Thaler, E.R., Cohen, N.A., Palmer, J.N. and Adappa, N.D., 2018, June. Preoperative Lund-Mackay computed tomography score is associated with preoperative symptom severity and predicts quality-of life outcome trajectories after sinus surgery. In International forum of allergy \& rhinology (Vol. 8, No. 6, pp. 668-675.

[30] Hopkins, C., Browne, J.P., Slack, R., Lund, V. and Brown, P., 2007. The Lund Mackay staging system for chronic rhinosinusitis: how is it used and what does it predict?. Otolaryngology-Head and Neck Surgery, 137(4), pp.555-561

[31] Cho, S.H., Kim, D.W. and Gevaert, P., 2016. Chronic rhinosinusitis without nasal polyps. The Journal of Allergy and Clinical Immunology: In Practice, 4(4), pp.575-582.

[32] Stevens, W.W., Schleimer, R.P. and Kern, R.C., 2016. Chronic rhinosinusitis with nasal polyps. The journal of allergy and clinical immunology: In practice, 4(4), pp.565-572. 